•植物园定位与发展战略专题・

\title{
植物利用研究与植物园的生命力
}

\author{
贺善安 ${ }^{*}$ 顾 姻 \\ (江苏省中国科学院植物研究所江苏省植物资源研究和利用重点实验室，南京 210014)
}

\section{Plant exploration research and botanical garden vitality}

\author{
Shan'an $\mathrm{He}^{*}$, Yin Gu \\ Jiangsu Provincial Key Laboratory of Plant Resources Research and Application, Institute of Botany, Jiangsu Province \\ and Chinese Academy of Sciences, Nanjing 210014
}

在世界植物园 400 余年的历史过程中, 其内容 不断扩展、深化与交融, 其作用因历史时期、自然 地域、经济发展程度、科学技术环境、社会结构和 公众的需求不同而时有相应的变化和侧重。17世纪 初全世界仅有几个植物园, 19世纪初有了20多个, 20 世纪初也只有百余个, 20 世纪中期有 600 多个, 但 到21世纪初猛增到2,000多个, 而今已超过3,000个 (He et al, 2017)。这样快的发展速度和如此之大的数 量, 加上它本身的结构又含有多种功能, 多样化是 必然的。但深入认识植物、栽培保育植物、发现利 用植物则是植物园的根本宗旨。在今后相当长的一 段历史时期里, 尤其是在生物多样性丰富的发展中 国家，这个目标仍为植物园的方向。

\section{1 植物园孕育和成长于人类利用植物的实 践之中}

在16世纪中叶文艺复兴的巅峰时期, 欧洲出现 了植物园这个新事物, 其前身很多都是被誉为“植 物园的摇篮” (He et al, 2017)的药用植物园固, 这些 早期植物园的创建人中也常常包含医药学家。意大 利的帕多瓦植物园和英国的切尔西药用植物园是 典型的范例, 诸多古老的植物园均有雷同的渊源。 由此可见植物园的出现是应人类利用植物之需。建 立植物园后, 尽力收集植物是所有植物园的共同特 点, 在欧洲一个面积不大的植物园, 如1公顷或几 公顷, 其收集量都普遍在四五千个甚至上万个分类

收稿日期: 2017-06-23; 接受日期: 2017-09-08

* 通讯作者 Author for correspondence. E-mail: sahe216@qq.com
单位。追求数量固然有皇室和富豪们好奇、炫耀的 因素, 但更重要的是发现新的有用植物的需要。到 20 世纪初, 世界植物园总数发展到100个左右, 仍 主要集中在欧洲, 而其提供新的有用植物资源的目 的越来越清楚, 尤其是战略性的经济植物和药用植 物等等, 实际上植物园就是在人类寻找有用植物的 实践中, 为产业发展提供植物资源的过程中迅速成 长壮大起来的。

然而植物园的本质并没有为多数人所真切地 认清。因为自古以来就认为高雅文明总是伴随着卓 越的园林，在公众的思想上，一提到“园”就很自然 地与优美的宜居环境和绿色的工作与活动的场所 相联系，一提到“园”就与 “美”和“游”联系在一起， 而淡化甚至忽略了植物园与一般花园和公园的区 别。然而植物园的这个“园”并非一般的园, 它是“植 物利用研究”的园地, 与“研” (科学研究)联系在一 起。植物园除了 “游”的功能外, 更重要的是它的 “研”的功能, 也是它区别于其他各种公园的特质。 植物园之所以要在广义“园”的体系中分化出一个分 支，是因“研”而生。尽管在发展的过程中，通过交 流、融入、开拓、提升可成为更为综合性的植物园, 但其主旨仍然是植物利用研究, 尤其是在物种层面 上的生物多样性研究。

植物园的首要任务就是根据各自的规划, 或所 谓任务书, 通过各种方法收集尽可能多的各式各样 的植物, 探求和发现可为人们利用的植物。出于这 
样的目的, 植物园总是把经过实地调查、直接由野 外采集的第一手植物材料视为最有价值的收集。完 整而符合标准的采集记录则是其科学价值的保证。 认识人类尚未认识的植物, 是植物园的最高追求。 这是植物利用研究的起点, 也是植物园的根本。

1954年国际植物园协会成立之时对植物园的 定义是: “一个向公众开放的, 其内的植物标有名牌 的园地”。2000年国际植物园保护联盟把植物园定 义为: “拥有活植物收集区, 并对收集区的植物进行 记录管理, 使之可用于科学研究、保护、展示和教 育的机构” (Wyse Jackson \& Sutherland, 2000)。尽管 后一个定义也还不够全面, 但已比当初的定义更明 确地表达了植物园的科研性质, 尤其强调了 “活植 物的收集”这个核心问题。

\section{2 植物园的生命力源于对新有用植物的发 现和利用}

数百年的历史告诉我们, 植物园贵在发现新的 有用植物。它们越对经济建设有贡献, 就越受到社 会的关注。

历史上欧洲是世界植物园的中心, 先是荷兰、 西班牙、葡萄牙等国趁其经济繁荣和世界航运兴起 的机会, 对自己在世界各地的殖民地频繁、深入地 搜索、引种所有能采集到的植物, 到18世纪下半叶 以来, 英国邱园逐步成为世界植物园的引领者, 并 形成一个搜集世界植物资源的体系。到20世纪初, 邱园已培养出数以百计的植物园主任, 派往东南 亚、印度、澳洲、加拿大等地, 主持其在殖民地的 皇家植物园。这个高贵、美丽、豪华的体系给人们 以优美植物环境的享受, 在精致、烂漫、令人陶醉 的环境里, 珍藏的是世界各地的植物资源。珍贵植 物资源的开发利用, 为殖民地带来了经济的繁荣和 就业的机会, 促进了社会的稳定。这个时期被称为 邱园的“黄金时期”。

欧洲早期的植物园多处于纬度较高的地区，而 从低纬度生物多样性丰富的殖民地引来的植物抗 寒性不强是常事, 因此温室就成为不可缺少的设 施。从邱园温室的发展情况来看, 初期为柑橘类植 物的引种建立了柑橘温室, 随着进一步开发利用棕 榈科经济植物的需要, 邱园标志性的棕榈温室于 19 世纪下半叶建成, 面积 2,000 多 $\mathrm{m}^{2}$, 但以后又扩建了 更大的温带植物温室。20世纪又建立了威尔士公主
温室、新高原植物温室, 以及澳洲植物温室、膜硕 植物温室、睡莲温室等等。可见邱园对引种的不遗 余力。现在温室已成为植物园的特征和必备的设施, 并往往把它当作标志性建筑。连帕多瓦这个古老的 植物园2015年也新建了一个 $3,000 \mathrm{~m}^{2}$ 的温室。

植物园在寻找新经济植物的历史上, 成果无数, 贡献关系到衣、食、住、行, 生、老、病、死, 工、 农、航天事业等等, 无法在此一一列举。最为著名 和具有划时代意义的成果就是战略植物资源橡胶 树(Hevea brasiliensis)的发现、引种、栽培、割胶, 一 直到橡胶产业链的形成。现在全球每年产生胶片 500 余万吨, 产品种类数以千计, 提供的就业机会、 产生的经济效益和战略意义的巨大是无庸置疑的。 如果没有植物园对巴西雨林里产胶植物的调查研 究选出原产巴西的橡胶树这个最有潜力的物种; 如 果没有对这个树种一系列生物学特性和繁殖、栽培 的研究, 对抗病种源的篮选及割胶技术的发明, 橡 胶产业是很难形成的。人们都不会忘记和低估硫化 作用对橡胶产业的贡献, 但是又有多少人认识和理 解当年新加坡植物园主任、被人称作研究橡胶树的 “疯子”的瑞德里先生? 疯子一词入木三分地勾画了 他对橡胶研究的执着。别小看了割胶的这一刀, 没 有这一刀就无法几十年如一日地把乳胶从树体内 取出来, 如不能持续稳定地取得乳胶, 也就没有资 源可供利用。我们常说植物园研究的“源头性”, 这 个例子可以说是很典型的了。植物园里的这种貌似 原始、初级的研究是不能被忽视的。发现和开发这 一个橡胶树种, 如果从1876年算起到形成产业, 花 了 40-50年时间。但是我们也不能孤立地看问题, 如 果没有邱园等植物园群体百余年广泛、大量的调查 研究、对几万种植物的引种栽培, 数以百计的技术 队伍的培训和巨大的收集资源植物的网络, 这种成 果也很难取得。应该说, 这样的成果是百年奋斗的 结果, 其长期性也是很可观的。

19世纪后期, 美国绅士亨利·萧和布瑞吞都是 在参观邱园后, 认识到植物资源对经济发展的潜力 以及植物园在科学、艺术、文化诸多方面综合实力 的魅力, 羡慕、激动、领悟之余, 才在回国后注巨 资兴建了著名的密苏里植物园和纽约植物园, 而其 现有规模及成果为世界所瞩目。

在我国, 从中华人民共和国成立以来, 植物园 在植物利用研究方面对工业、农业以及国防做出了 
数以百计的贡献和成果(He, 2002; He et al, 2017)。 诸如: 山葡萄(Vitis amurensis)的抗寒种质资源、薯 蓣属(Dioscorea)的㿝素资源、本土的草坪草资源及 神农香菊(Dendranthema indicum var. aromaticum) 资源、固沙抗旱植物资源的生态利用; 速生和优质 材用树种的引种驯化、檀香(Santalum album)的引 种、特有民族药用植物资源包括罗汉果 (Siraitia grosvenorii)等的发掘与利用, 都对经济发展起着重 要作用。其中有一些, 如我国特产狝猴桃属 (Actinidia) 资源的研究利用, 无论是对经济发展还 科学技术水平进步的贡献, 都居于世界领先的地 位。凡此种种, 不难看出植物园对国家经济发展和 造福人民的作用。所以说, 植物园的辉煌是植根于 植物利用研究之中, 它的生命力源于促进经济繁荣 和社会进步的科研之中。植物园素以作出令人瞩目 的利用植物的成绩而受人称道。

\section{3 正确认识物种保护, 加强植物利用研究}

20 世纪70年代以后, 全球生态危机出现, 人们 发现植物资源再也不是取之不尽, 用之不竭, 物种 的灭绝正以上千倍于以往的常态速度发展时, 物种 保护的使命提上了议事日程。1985年在西班牙大加 那里岛召开的世界植物园大会, 首次发布了《大加 那里岛宣言》(The Gran Canaria Declaration, Bramwell et al, 1987), 提出了 “拯救植物就是拯救人类自 己”的口号, 并且把物种保护的希望寄托在植物园 的身上。《宣言》开宗明义地指出, “数百年来, 植 物园一直是植物多样性科学研究的主要中心, 它是 一个植物引种和评价机构, 为农、林、园艺和药物 提供各种新的植物”。同时发出了警告, 要保护植物, 并把它认定为对植物园的新挑战。植物园被誉为拯 救植物的“诺亚方舟”。在全球大声疾呼要拯救植物 的呼声中, 全球植物园掀起了一个新热潮: 全力开 展物种保护的研究和行动。中国植物园在20世纪 80 年代《大加那里岛宣言》发表后, 也及时地赶上了 世界植物园的步伐。物种保护成了全球植物园的头 号任务。自此, 西方著名植物园明显地淡化了经济 植物利用的研究, 在致力于物种保护行动的同时, 大力发展科普教育, 尤其是环境教育的内容。植物 园显现出了以面向城市公众的需要和加强科普教 育为主流的倾向, 有逐渐向文化机构倾斜的迹象, 甚至提出要“重新确定植物园的作用” (BGCI,
2010)。

其实, 物种利用和物种保护是一个事物的两 面。利用可以促进保护, 保护是为了持续利用。植 物园在面对物种保护挑战时, 并不应排斥利用研究, 而是应更为科学地研究可持续利用, 应该挑起利用 和保护的两副重担。试问: 植物园为何被誉为保护 植物的“诺亚方舟”? 那是因为人们发现植物物种正 在野外快速灭绝时, 世界植物园里却保存着约 80,000 种以上的植物。这数以万计的植物是为什么 进入植物园的? 是为了物种保护吗? 不是! 是几百 年来人类研究植物利用的结果, 当时人们还不曾意 识到保护的必要性。可见利用促进了保护。例如: 对 银杏(Ginkgo biloba)这个顶级古老的物种而言, 世 界著名植物学家、英国邱园前主任克兰在他新近出 版的著作中写道: 通过栽培, “人类已经大大增加了 银杏长期生存的机会” (Crane, 2016)。

对于中国和其他生物多样性丰富的发展中国 家的植物园来说, 还应不遗余力地继续经济植物利 用的研究, 要做出成绩, 要有显示度, 以争取社会 的支持。根据邱园2016年的全球植物现状评估报告 (https://stateoftheworldsplants.com/2016/report/sotwp _2016.pdf/)：全世界的有用植物共达31,128种，而 2015年全球发现的新物种共有2,034种之多。根据南 京中山植物园的统计, 中国的经济植物(包括本土 和引进的)超过14,000种(含亚种、变种), 约占世界 有用植物总数的 $40 \%$ 以上。对经济植物的开发和利 用研究还有很大的空间。人们在 1985 年提出植物园 的物种保护任务时, 就发现全球植物园的分布与植 物多样性的分布不成比例, 这是所有植物学家一致 公认的、无可辩驳的事实。究其原因, 无非是建立 植物园需要投入, 而植物多样性丰富的地区经济和 科技发展大都比较滞后, 无力建设一个既联系当前 经济效益, 又能远虑未来持续发展的植物园这项造 福人民的千秋功业。

植物园是经济繁荣和社会进步的产物, 反过来, 它又是促进经济发达和社会文明的工具。在“一带 一路”战略影响所及的范围内, 随着经济发展的提 升, 势必大有植物园发展的机会与空间, 我国植物 园应该不失时机地发挥应有的作用, 总结历史经验, 加强国际合作, 因地制宜地开展植物利用研究。过 去的几百年, 西方著名植物园是把资源植物引种到 经济和科技发达的地区去研究; 今天, 我们则可以 
就在资源植物多样性丰富的原产地开展保护和利 用的全面研究, 收效将更加显著, 也更接地气。我 们应把握好这个历史的转折, 优化、扩建、创建更 多更好的植物园。

现在全世界的植物园有3,000多个, 且还会迅 速增长, 其多样性及形式和内容的分化是理所当然 的。洪德元院士提出的“三个哪些” (洪德元, 2016) 直指植物利用研究, 是植物园的本质问题, 是植物 园体系必须遵循的原则。鉴于植物利用研究的长期 性、源头性以及成果评估的不确定性, 对植物园的 植物利用研究支撑体系和政策的改革与创新也势 在必行，这将密切关系着植物园的方向。

人类对植物资源的需求是全方位的。当代对有 用植物发掘和利用研究的两大重点可能是药用植 物(包括功能性植物)和环境植物(包括观赏植物)。与 以往不同的是: 在资源植物开发过程中应注意避免 对生态环境的破坏; 消除单一栽培的副作用; 检测 和杜绝外来入侵物种的风险; 要强调可持续发展。 由于科学技术的快速发展, 研究手段的多样和高、 精、尖技术的使用, 植物利用研究已往往不可能单独 在植物园内完成, 合作研究已成为不可避免的途径,
植物园可能比以往更要有甘当配角的思想准备。

\section{参考文献}

BGCI (2010) Redefining the Role of Botanic Gardens-Towards A New Social Purpose. BGCI, Surrey.

Crane P (translated by YH Hu, QF Zhang) (2016) Ginkgo: The Tree That Time Forgot, p. 227. Higher Education Press, Beijing. (in Chinese) [胡永红, 张庆费 (译) (2016) 银杏: 被时间遗忘的树种, 227页. 高等教育出版社, 北京.]

He SA (2002) Fifty years of botanical gardens in China. Acta Botanica Sinica, 44, 1123-1133.

He SA, Zhang ZS, Gu Y, Xia B, Chu RZ, Yu H (2017) Phytohortology. Science Press, Beijing.

Hong DY (2016) Three "What": mission of a botanic garden. Biodiversity Science, 24, 728. (in Chinese) [洪德元 (2016) 三个“哪些”: 植物园的使命. 生物多样性, 24, 728.]

Bramwell D, Hamann O, Heywood V, Synge H (1987) The Declaration of Gran Canaria. In: Botanical Gardens and the World Conservation Strategy (eds Bramwell D, Hamann O, Heywood V, Synge H), p. 357. IUCN and Academic Press, London.]

Wyse Jackson P, Sutherland LA (2000) International Agenda for Botanic Gardens in Conservation. BGCI, Surrey.

(责任编委: 龙春林 责任编辑: 黄祥忠) 